Article

\title{
Graphene Quantum Dots Doped PVDF(TBT)/PVP(TBT) Fiber Film with Enhanced Photocatalytic Performance
}

\author{
Fubao Zhang ${ }^{1}$, Chen Yang ${ }^{1}$, Xiao-Xiong Wang ${ }^{1}, \mathbf{R u ~ L i}^{1}$, Zhong Wan ${ }^{2}$, Xianming Wang ${ }^{2}$, \\ Yong Wan ${ }^{1, *}$, Yun-Ze Long ${ }^{1, *}$ and Zhongyu Cai ${ }^{3,4,5,6, *}$ \\ 1 College of Physics Science, Qingdao University, Qingdao 266071, China; fbzhang18@163.com (F.Z.); \\ yangchen_921314@163.com (C.Y.); wangxiaoxiong69@163.com (X.-X.W.); liruouc@163.com (R.L.) \\ 2 State Key Laboratory of Marine Coatings, Marine Chemical Research Institute Co., Ltd., \\ Qingdao 266071, China; qdwanzhong@163.com (Z.W.); wxm133701@163.com (X.W.) \\ 3 Research Institute for Frontier Science, Beihang University, Beijing 100191, China \\ 4 Beijing Advanced Innovation Center for Biomedical Engineering, Beihang University, Beijing 100191, China \\ 5 School of Space and Environment, Beihang University, Beijing 100191, China \\ 6 Department of Chemistry, University of Pittsburgh, Pittsburgh, PA 15260, USA \\ * Correspondence: wanyongqd@hotmail.com (Y.W.); yunze.long@163.com (Y.-Z.L.); caizy@buaa.edu.cn (Z.C.)
}

Received: 21 November 2019; Accepted: 9 January 2020; Published: 14 January 2020

check for updates

\begin{abstract}
We report the fabrication of polyvinylidene fluoride (tetrabutyl titanate)/polyvinyl pyrrolidone ((tetrabutyl titanate))-graphene quantum dots [PVDF(TBT)/PVP(TBT)-GQDs] film photocatalyst with enhanced photocatalytic performance. The polyvinylidene fluoride (tetrabutyl titanate)/polyvinyl pyrrolidone ((tetrabutyl titanate)) [PVDF(TBT)/PVP(TBT)] film was first prepared with a dual-electrospinning method and then followed by attaching graphene quantum dots (GQDs) to the surface of the composite film through a hydrothermal method. Later, part of the PVP in the composite film was dissolved by a hydrothermal method. As a result, a PVDF(TBT)/PVP(TBT)-GQDs film photocatalyst with a larger specific surface area was achieved. The photocatalytic degradation behavior of the PVDF(TBT)/PVP(TBT)-GQDs film photocatalyst was examined by using Rhodamine $\mathrm{B}$ as the target contaminant. The PVDF(TBT)/PVP(TBT)-GQDs photocatalyst showed a higher photocatalytic efficiency than PVDF(TBT)- $\mathrm{H}_{2} \mathrm{O}$, PVDF(TBT)/PVP(TBT)- $\mathrm{H}_{2} \mathrm{O}$, and PVDF(TBT)-GQDs, respectively. The enhanced photocatalytic efficiency can be attributed to the broader optical response range of the PVDF(TBT)/PVP(TBT)-GQDs photocatalyst, which makes it useful as an effective photocatalyst under white light irradiation.
\end{abstract}

Keywords: electrospinning; nanofiber film; tetrabutyl titanate composites; graphene quantum dots; visible light photocatalysis

\section{Introduction}

In 1972, Fujishima and Honda first discovered that titanium dioxide $\left(\mathrm{TiO}_{2}\right)$ had photocatalytic properties [1]. $\mathrm{TiO}_{2}$ photocatalysts have been extensively investigated in the fields of water splitting to produce hydrogen [2-6], organic dye decomposition [7-9], sewage purification [10], and air filtration [11] due to its non-toxicity, low cost, high activity, and high efficiency [2-5,12]. Furthermore, $\mathrm{TiO}_{2}$ has a relatively broad bandgap, which is about $3.2 \mathrm{eV}$. This causes the pure $\mathrm{TiO}_{2}$ photocatalyst to only absorb light within the ultraviolet region. However, ultraviolet light only accounts for $5 \%$ of the sunlight. The low-usage of sunlight and the low separation rate of photoexcited electron-hole pairs significantly lower its photocatalytic efficiency and hinder the application of $\mathrm{TiO}_{2}$ photocatalysts in practice [13-16]. In addition to $\mathrm{TiO}_{2}$, there are many other types of common photocatalysts including 
$\mathrm{ZnO}, \mathrm{WO}_{3}, \mathrm{Bi}_{2} \mathrm{O}_{3}, \mathrm{Fe}_{2} \mathrm{O}_{3}, \mathrm{CdS}, \mathrm{CuS}, \mathrm{PbS}, \mathrm{ZnS}, \mathrm{SnO}_{2}$, and $\mathrm{SrTiO}_{3}$ [12]. However, some of these materials are expensive, and most of these materials are susceptible to chemical or photochemical corrosion, which dramatically limits their use for practical photocatalysis.

To overcome these shortcomings of $\mathrm{TiO}_{2}$ photocatalysts, scientists have made a variety of achievements on $\mathrm{TiO}_{2}$ photocatalysts to improve their catalytic performance. These methods include increasing its specific surface area [17], semiconductor composite, noble metal deposition [18], and metal/nonmetal ion doping [19-22]. However, some precursors of heterojunction semiconductors such as transition metal ions may cause environmental pollution. Recently, carbon quantum dots (CQDs) as green photocatalysts or photocatalyst promoters have been widely investigated [23-25]. CQDs have strong absorption in a broad spectral range and have excellent photobleaching stability, low cytotoxicity, and up-conversion luminescence properties [26-29]. Graphene quantum dots (GQDs) have higher crystallinity than conventional CQDs. The high degree of crystallinity allows GQDs to show excellent electron transport ability, thereby extending the carrier lifetime [30-33]. However, compared to solar cells [34-36], biosensing [37,38], and bioimaging [39-41], there are fewer studies on GQDs as photocatalysts, which is getting more and more attention from researchers.

Electrospinning is an excellent technique for preparing polymeric materials, which can be used to produce fiber films of tens to hundreds of nanometers in diameter. The fiber film fabricated with electrospinning generally has a large specific surface area and can be used to immobilize a large amount of the photocatalyst to improve photocatalytic performance [42]. Among various polymers, polyvinylidene fluoride (PVDF) [43-45] is one of the most commonly used photocatalyst supports due to its good mechanical strength, chemical, and thermal stabilities [46,47]. In addition, PVDF is also readily available and relatively inexpensive, which facilitates its wide use in various applications [45,48]. As a synthetic water-soluble polymer compound, polyvinyl pyrrolidone (PVP) $[49,50]$ shows the general properties of water-soluble polymer compounds and excellent biocompatibility, and does not irritate skin, mucous membranes, eyes, etc.

In this study, we mixed PVDF and water-soluble PVP with tetrabutyl titanate (TBT) and then electrospun it into a nanofiber film, polyvinylidene fluoride (tetrabutyl titanate)/polyvinyl pyrrolidone ((tetrabutyl titanate)) [PVDF(TBT)/PVP(TBT)]. PVP in the hybrid nanofiber film can be dissolved by deionized water to form pores [51,52]. Then, GQDs are deposited onto the PVDF(TBT)/PVP(TBT) film through a hydrothermal reaction of the film with anhydrous glucose. The resulting polyvinylidene fluoride (tetrabutyl titanate)/polyvinyl pyrrolidone ((tetrabutyl titanate))-graphene quantum dots [PVDF(TBT)/PVP(TBT)-GQDs] film photocatalyst was shown to have higher photodegradation performance to Rhodamine B compared to other similar photocatalysts.

\section{Experimental Section}

\subsection{Materials}

Acetone and polyvinylidene fluoride (PVDF, Mw $\approx 550,000$ ) were purchased from Sanaifu New Material Technology Co., Ltd. (Shanghai, China). Polyvinyl pyrrolidone (PVP, Mw $\approx 1,300,000$ ) and Rhodamine B (RhB) were purchased from Aladdin Chemical Co., Ltd. (Shanghai, China). Ethanol (99.7\%), N,N-dimethylformamide (DMF), tetrabutyl titanate (TBT), sulfuric acid (mass fraction of $95 \%$ to $98 \%$ ), and anhydrous glucose were purchased from Sinopharm Chemical Reagent Co., Ltd. (Shanghai, China). Deionized water was manufactured using an UPK-I-10T series Ultrapure water machine (Sichuan, China). All of the chemical reagents were used as received without further purification.

\subsection{Preparation of $P V D F(T B T) / P V P(T B T)$ Nanofibrous Films}

$4.0 \mathrm{~g}$ of polyvinylidene fluoride (PVDF) was weighed and poured into a beaker, and $10 \mathrm{~g}$ of $\mathrm{N}, \mathrm{N}$-dimethylformamide (DMF), $10 \mathrm{~g}$ of acetone, and $2 \mathrm{~mL}$ of tetrabutyl titanate (TBT) were sequentially added to the beaker. The beaker was sealed and placed on a magnetic stirrer, and stirred in a water 
bath at a temperature of $40^{\circ} \mathrm{C}$ for $1 \mathrm{~h}$ to obtain a homogeneous PVDF(TBT) solution. Two grams of polyvinyl pyrrolidone (PVP) was weighed into a beaker, and $13.38 \mathrm{~g}$ of absolute ethyl alcohol and $2 \mathrm{~mL}$ of TBT was sequentially added to the beaker. The beaker was sealed and placed on a magnetic stirrer for $2 \mathrm{~h}$ to obtain a homogeneous PVP(TBT) solution. In the preparation of the PVDF(TBT)/PVP(TBT) fiber film, as shown in Scheme 1A, the PVDF(TBT) solution was first electrospun uniformly on the surface of the roller. After $1 \mathrm{~h}$, the PVDF(TBT) and PVP(TBT) solutions were uniformly electrospun on the roller as shown in Scheme 1B. The parameters of the PVDF(TBT) and PVP(TBT) solutions during electrospinning to prepare the films are as follows: voltages of $15 \mathrm{kV}$ and $18 \mathrm{kV}$, advancing speed of $25 \mu \mathrm{L} / \mathrm{min}$ and $18 \mu \mathrm{L} / \mathrm{min}$, respectively, and the distance between the syringe and the roller was $15 \mathrm{~cm}$. After electrospinning for $12 \mathrm{~h}$, the PVDF(TBT)/PVP(TBT) film was removed from the roller. The peeled film was placed in a drying oven and dried at $60^{\circ} \mathrm{C}$ for $6 \mathrm{~h}$. After lowering the temperature in the drying oven to room temperature, the PVDF(TBT)/PVP(TBT) film was taken out and cut into $2 \mathrm{~cm} \times 2 \mathrm{~cm}$.
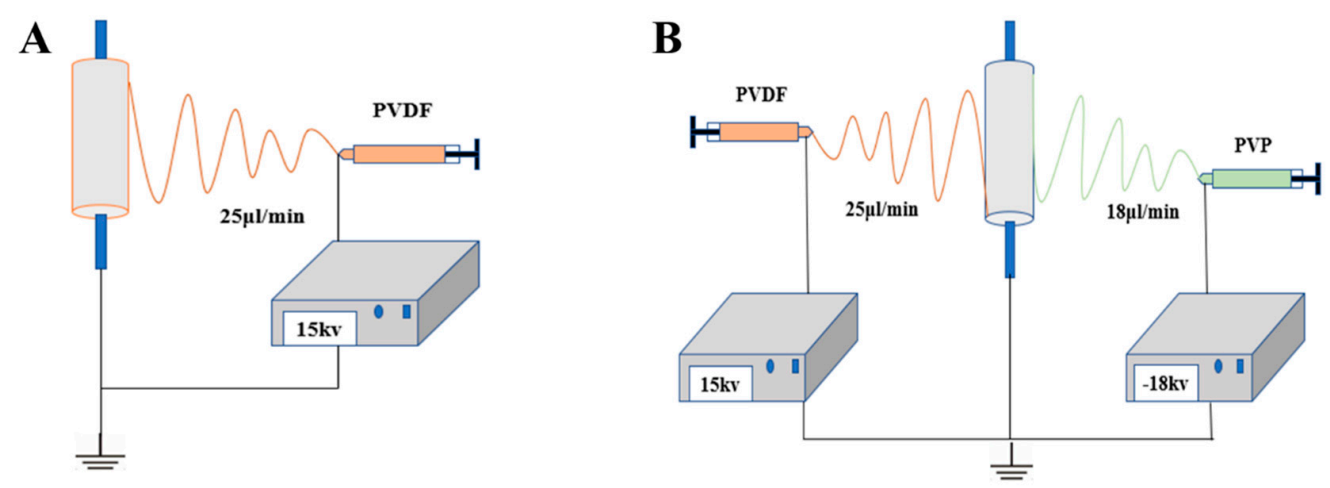

Scheme 1. Schematic illustration of electrospinning: (A) PVDF(TBT) and (B) PVDF(TBT)/PVP(TBT) film spinning.

\subsection{Preparation of Graphene Quantum Dots}

CQDs refer to carbon nanomaterials with a particle size of $1 \mathrm{~nm}$ to $100 \mathrm{~nm}$. CQDs look like small dots and are generally spherical. GQDs not only possess the superior properties of graphene, but also have excellent performance of quantum dots [34]. We used a hydrothermal method to prepare the GQDs [53]. First, $1.5 \mathrm{~g}$ of anhydrous glucose and $10 \mathrm{~mL}$ of deionized water was added to a small beaker and stirred with a magnetic stirrer for $10 \mathrm{~min}$. Thereafter, $12 \mathrm{~mL}$ of concentrated sulfuric acid was added dropwise to a small beaker and stirring was continued for $15 \mathrm{~min}$. The solution in a small beaker was poured into the stainless-steel autoclave and sealed. The stainless-steel autoclave was placed in a drying oven and maintained at $200{ }^{\circ} \mathrm{C}$ for $3 \mathrm{~h}$. After $3 \mathrm{~h}$, the drying oven was turned off and the drying oven was naturally cooled down to room temperature. The stainless-steel autoclave was removed and filtered to obtain a quantum dot solution.

\subsection{Fabrication of PVDF(TBT)/PVP(TBT)-GQDs Composite Film}

A total of $1.5 \mathrm{~g}$ of anhydrous glucose was placed in a small beaker, then $10 \mathrm{~mL}$ of deionized water was added to the small beaker and stirred for $15 \mathrm{~min}$. After the solution became clear, $12 \mathrm{~mL}$ of concentrated sulfuric acid was dropped into the small beaker and stirring was continued for $15 \mathrm{~min}$. The solution in the beaker was naturally cooled down to room temperature and then poured into the stainless-steel autoclave. Next, a $2 \mathrm{~cm} \times 2 \mathrm{~cm}$ section of PVDF(TBT)/PVP(TBT) film was put in the stainless-steel autoclave. The sealed stainless-steel autoclave was placed in a constant temperature drying oven, and the temperature of the drying oven was raised to $200{ }^{\circ} \mathrm{C}$ and held for $3 \mathrm{~h}$. After $3 \mathrm{~h}$, the drying oven was closed and the temperature in the drying oven allowed to naturally cool down to room temperature. The stainless-steel autoclave was opened and the PVDF(TBT)/PVP(TBT) film was taken out. The resultant PVDF(TBT)/PVP(TBT) film was rinsed to neutral with deionized water 
and allowed to air dry. The residue in the stainless-steel autoclave was filtered to obtain a solution of quantum dots.

The synthesis process of the PVDF(TBT)/PVP(TBT)-GQDs composite is shown in Scheme 2. We first used two electrospinning machines to produce the PVDF(TBT)/PVP(TBT) film (Scheme 1B). The prepared PVDF(TBT)/PVP(TBT) film was placed in a drying oven and dried at $60^{\circ} \mathrm{C}$ for $6 \mathrm{~h}$. The dried film was cut into squares of $2 \mathrm{~cm} \times 2 \mathrm{~cm}$. The stirred glucose solution was added to the reaction kettle, and a $2 \mathrm{~cm} \times 2 \mathrm{~cm}$ film was also placed in the stainless-steel autoclave. The stainless-steel autoclave was sealed, placed in a drying oven, and dried at $200{ }^{\circ} \mathrm{C}$ for $3 \mathrm{~h}$. The film was removed from the stainless-steel autoclave and rinsed with deionized water until neutral. The rinsed film was naturally dried to obtain PVDF(TBT)/PVP(TBT)-GQDs film.

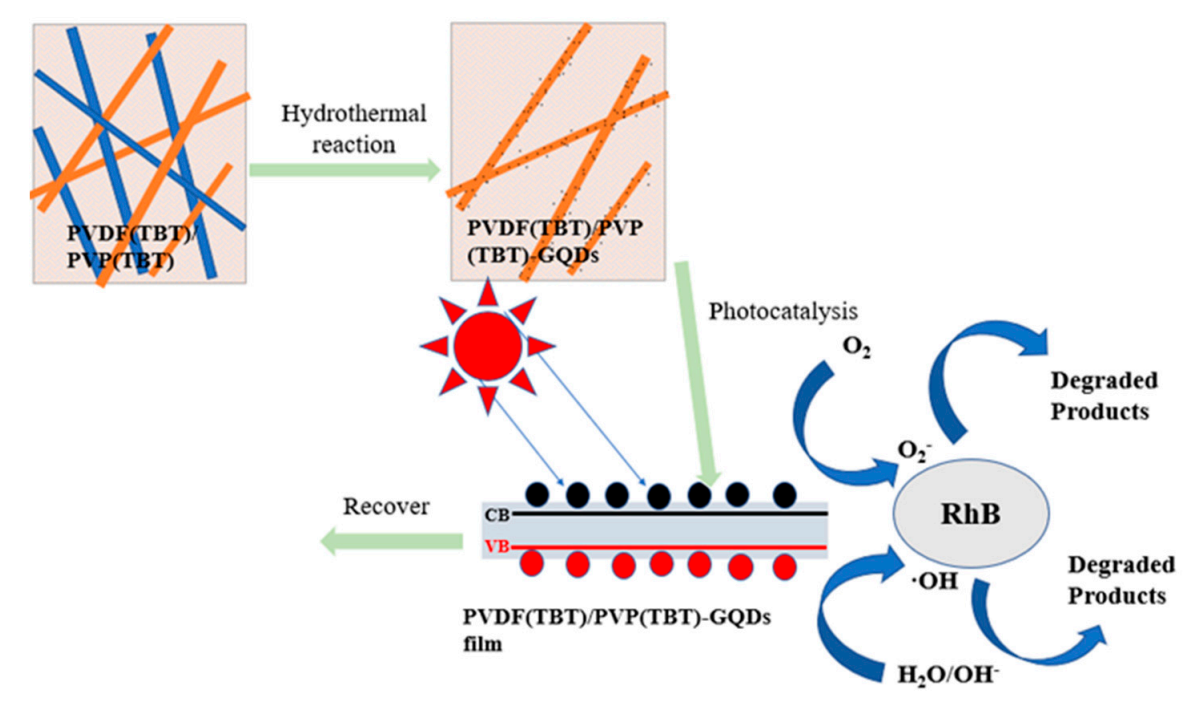

Scheme 2. Synthesis process diagram of PVDF(TBT)/PVP(TBT)-GQDs film and photocatalytic reaction mechanism. Here the orange lines denote PVDF (TBT) fibers, blue lines denote PVP (TBT) fibers, and the black dots represent GQDs.

\subsection{Characterization}

The microstructure of the resulting fiber film was measured with a scanning electron microscope (SEM, JSM-6390, JEOL, Tokyo, Japan). The morphology and size of the GQDs were observed using a transmission electron microscopy (TEM, H-7650, Hitachi, Tokyo, Japan). The absorbance of the reaction solution can be characterized by an ultraviolet-visible spectrophotometer (UV-Vis 3100, Mapada, Shanghai, China). Among them, the scanning wavelength range was $200 \mathrm{~nm}$ to $800 \mathrm{~nm}$, and the resolution was $1 \mathrm{~nm}$. The absorption spectrum of the prepared photocatalyst was analyzed using a T9 type UV-Visible spectrophotometer (DRS, T9, Persee, Beijing, China) with a scanning wavelength range of $200 \mathrm{~nm}$ to $800 \mathrm{~nm}$. An X-ray diffractometer (XRD, Rigaku Smart Lab (3 kW), Hitachi, Japan.) was used to confirm the substance elements in the sample. The Brunauer-Emmett-Teller (BET, Autosorb iQ3, Quantachrome, Shanghai, China) measures the specific surface area of a photocatalyst by $\mathrm{N}_{2}$ adsorption-desorption. The fluorescence characteristics of GQDs were measured using a fluorescence spectrometer (PL, F-4600, Hitachi, Tokyo, Japan). X-ray photoelectron spectroscopy (XPS, EscaLab 250Xi, Thermo Fisher Scientific, Waltham, MA, USA) was measured at a 01 emission angle using a monochromatic $\mathrm{Al} \mathrm{Ka}$ source (Ephoton $=1486.6 \mathrm{eV}), 10 \mathrm{~mA}$ filament current, and $14.7 \mathrm{keV}$ filament voltage source energy calibration.

\subsection{Photocatalytic Activity}

A PVDF(TBT)/PVP(TBT)-GQDs photocatalyst was placed on a photochemical reactor for the Rhodamine $\mathrm{B}(\mathrm{RhB})$ degradation experiments. In specific, RhB was selected as a model sample in 
the photocatalytic experiment. The various catalysts prepared were placed in an $80 \mathrm{~mL}$ quartz tube containing $40 \mathrm{~mL}$ of a $15 \mathrm{mg} / \mathrm{L} \mathrm{RhB}$ solution. The quartz tubes were numbered and put into the photochemical reactor (XPA-7(G8) multi-tube stirring photochemical reactor, Xujiang electromechanical company, Nanjing, China). To improve the accuracy of the test, a blank test without a photocatalyst was used as a reference. The photochemical reactor was equipped with an $800 \mathrm{~W}$ xenon lamp as a light source. In the experiment, the photocatalyst and $\mathrm{RhB}$ solution in the quartz cuvette were first stirred in the dark for $30 \mathrm{~min}$ to achieve the adsorption-desorption equilibrium. Then, $4 \mathrm{~mL}$ of the reaction solution was taken out of the quartz cuvette every $30 \mathrm{~min}$. The reaction solution was centrifuged to remove the photocatalyst. The absorbance of the reaction solution was measured with a UV-Vis spectrophotometer. The measured solution in the quartz cuvette was put back into the photochemical reactor. After $30 \mathrm{~min}$, the photochemical reactor was closed and the reaction solution was taken out for measurement. The above operation was repeated six times.

\section{Results and Discussion}

\subsection{Synthesis of GQDs}

Figure 1 shows the photoluminescence spectrum of GQDs in the wavelength range of $375 \mathrm{~nm}$ to $600 \mathrm{~nm}$. As shown in Figure 1, the fluorescence peak position of the sample was about $430 \mathrm{~nm}$ (yellow dotted line in the figure), and as the excitation wavelength increased, the emission intensity first increased and then decreased. It can be seen that the emission intensity was the strongest under the excitation of light with a wavelength of $360 \mathrm{~nm}$, and the emission intensity under excitation of light with a wavelength of $310 \mathrm{~nm}$ was weak. GQDs emit bright blue fluorescence when exposed to $365 \mathrm{~nm}$ ultraviolet light.

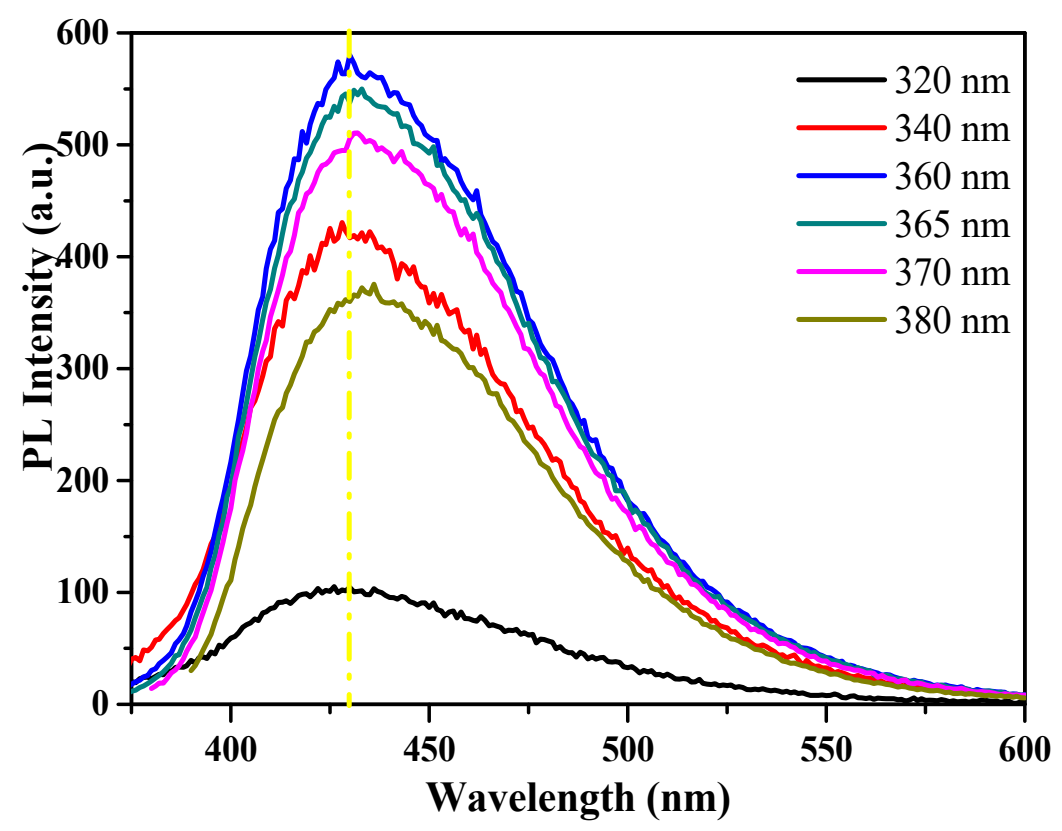

Figure 1. Photoluminescence spectroscopy of graphene quantum dots excited by the light of different wavelengths.

From Figure 2A, we can see the luminescence image of the GQDs under UV light at $365 \mathrm{~nm}$. Additionally, from the TEM image of GQDs (Figure 2B,C), the statistical analysis of the TEM images gave rise to a particle size distribution of the GQDs (as shown in Figure 2D). From Figure 2D, we can observe that the size distribution of the GQDs ranged from 1.8 to $3.0 \mathrm{~nm}$. 


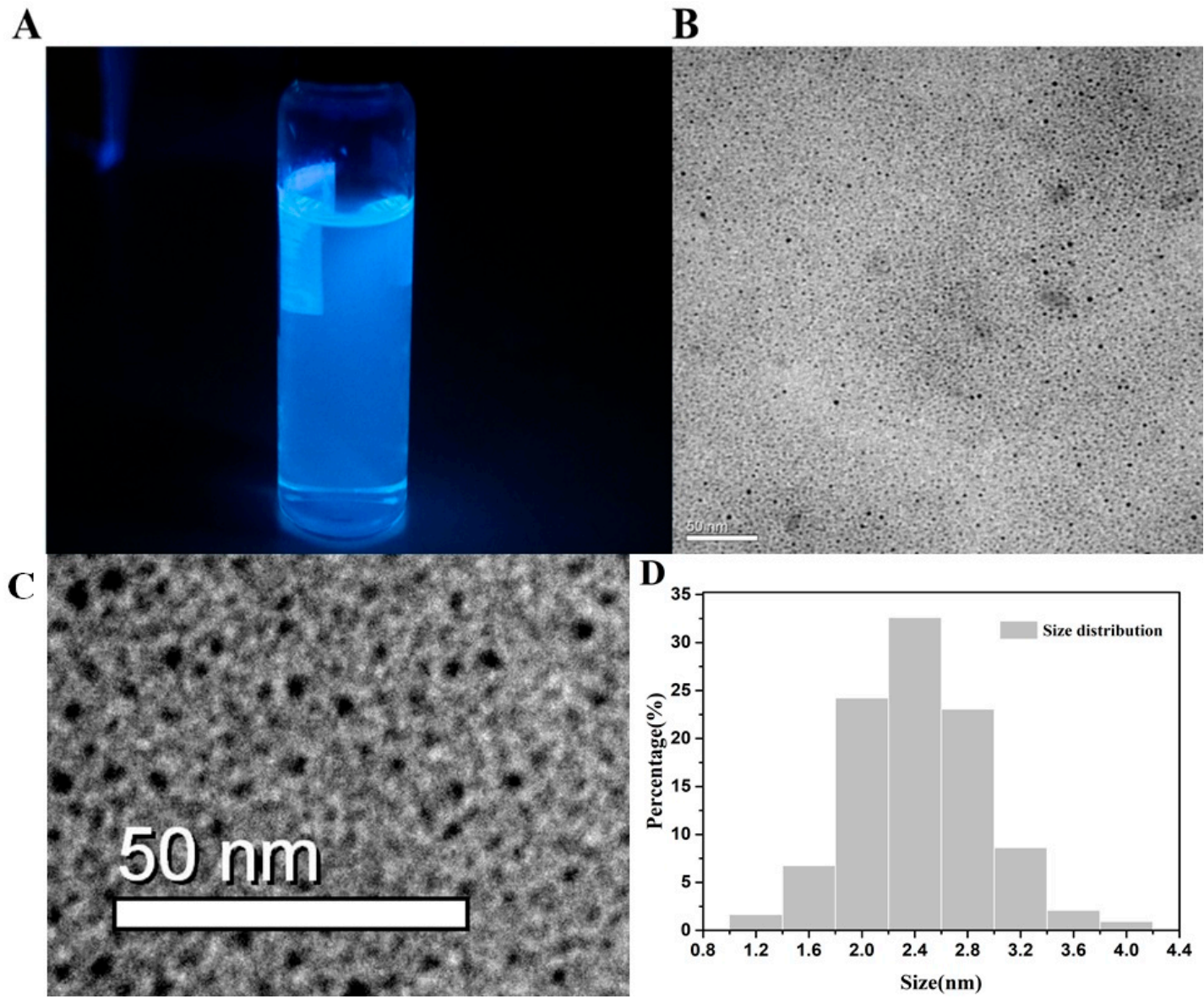

Figure 2. (A) Photograph of the GQDs under $365 \mathrm{~nm}$ ultraviolet light; (B,C) are TEM images of GQDs at low and high magnifications; and (D) the size distribution chart of the GQDs.

\subsection{Synthesis of $P V D F(T B T) / P V P(T B T)-G Q D s$}

We hydrothermally processed the PVDF(TBT)/PVP(TBT) film to form the PVDF(TBT)/PVP(TBT)-GQDs photocatalyst. The surface morphology of the prepared photocatalyst was observed by SEM. Figure 3A shows an SEM image of the pure PVDF(TBT) fiber created by electrospinning. As can be seen, the PVDF(TBT) fiber diameter was a few micrometers and the fiber surface was relatively smooth. Furthermore, the orientation of the PVDF(TBT) fibers was random and the fibers were interwoven to form a non-woven fiber film. Figure 3B,C are SEM images of the PVDF(TBT)/PVP(TBT) photocatalyst at different magnifications. From Figure 3B, we can clearly see that some fibers were intertwined. The higher magnification SEM image demonstrates the entanglement between the fibers (Figure 3C). As shown in Figure 3A, there was no entanglement when electrospinning the PVDF(TBT) film. Therefore, when performing electrospinning to produce the PVDF(TBT)/PVP(TBT) nanofiber (Scheme 1B), the two intertwined fibers produced must be PVDF(TBT) and PVP(TBT) fibers. Therefore, in the PVDF(TBT) and PVDF(TBT)/PVP(TBT) films, dissolving PVP fibers creates a gap at the original positions of PVP, thereby increasing the specific surface area of the film. Among them, PVDF(TBT)- $\mathrm{H}_{2} \mathrm{O}$ and PVDF(TBT)/PVP(TBT)- $\mathrm{H}_{2} \mathrm{O}$ achieved the effect of dissolving PVP by immersing the film in deionized water. PVDF(TBT)-GQDs and PVDF(TBT)/PVP(TBT)-GQDs dissolve PVP during the hydrothermal preparation of quantum dots. Comparing Figures $3 \mathrm{D}$ and $3 \mathrm{~A}$, we found that there were some small particles on the surface of the PVDF(TBT) fiber in Figure 3D. Since the PVDF(TBT)-GQDs films were hydrothermally prepared based on PVDF(TBT) films, it can be concluded that the small particles in Figure 3D are GQDs. Figure $3 \mathrm{E}, \mathrm{F}$ are SEM images of the PVDF(TBT)/PVP(TBT)- $\mathrm{H}_{2} \mathrm{O}$ and PVDF(TBT)/PVP(TBT)-GQDs, 
respectively. $\mathrm{PVDF}(\mathrm{TBT}) / \mathrm{PVP}(\mathrm{TBT})-\mathrm{H}_{2} \mathrm{O}$ was prepared by immersing the $\mathrm{PVDF}(\mathrm{TBT}) / \mathrm{PVP}(\mathrm{TBT})$ film in deionized water for $12 \mathrm{~h}$ and dried in air. As can be seen from Figure 3E, the PVP fibers in the $\mathrm{PVDF}(\mathrm{TBT}) / \mathrm{PVP}(\mathrm{TBT})-\mathrm{H}_{2} \mathrm{O}$ film dissolved because the PVDF(TBT)/PVP(TBT)- $\mathrm{H}_{2} \mathrm{O}$ film had been soaked in deionized water. Dissolved PVP can increase the specific surface area of the fiber film and thereby improve its photocatalytic performance. Similarly, as shown in Figure 3F, PVP fibers in PVDF(TBT)/PVP(TBT)-GQDs were also dissolved. In the hydrothermal preparation of GQDs, PVP in the PVDF(TBT)/PVP(TBT)-GQDs fiber film is in contact with water, resulting in partial PVP dissolution.

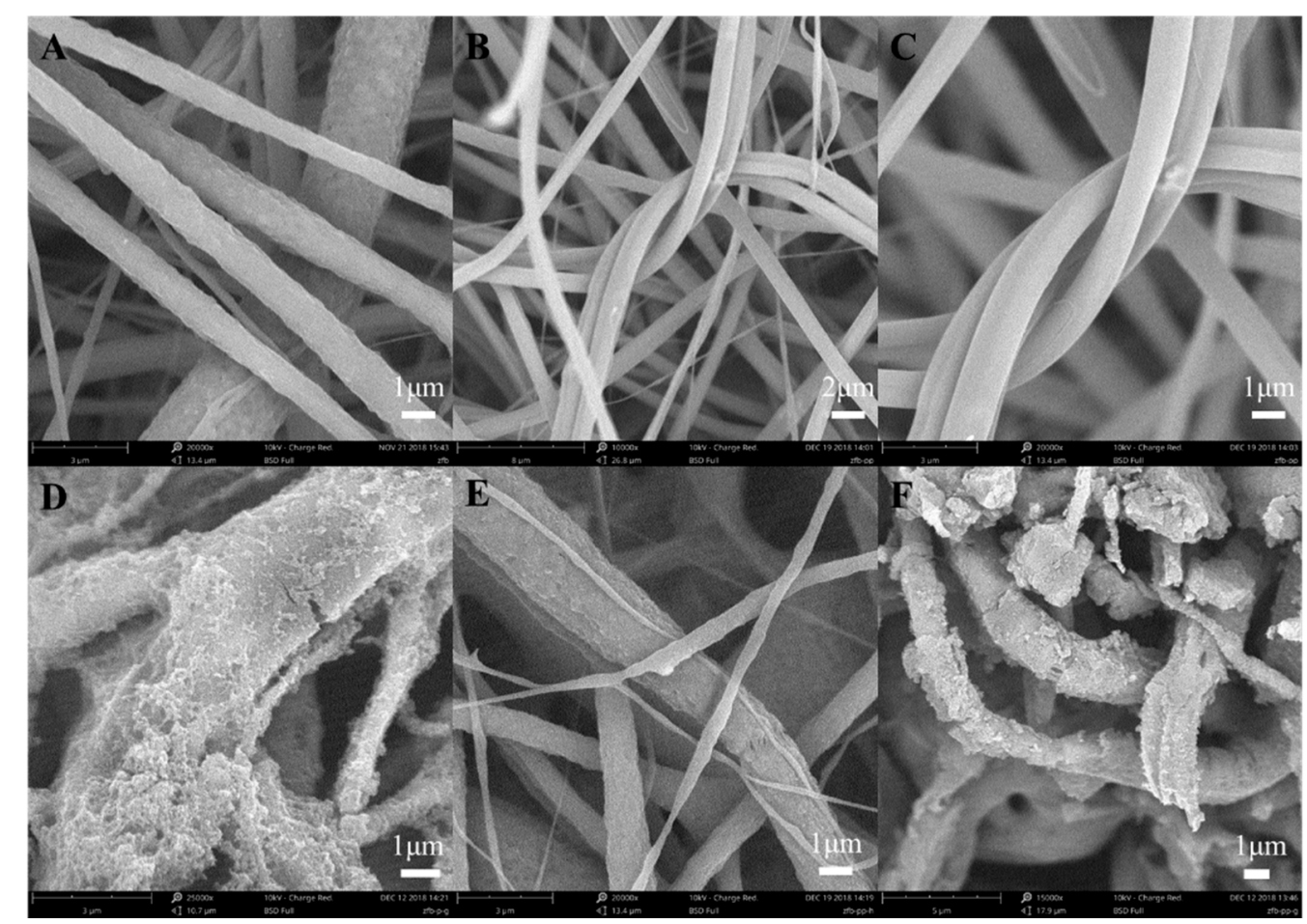

Figure 3. SEM images of (A) single electrospinning PVDF(TBT) nanofiber; (B) PVDF(TBT)/PVP(TBT) nanofiber; (C) PVDF(TBT)/PVP(TBT) nanofiber; (D) PVDF (TBT)-GQDs nanofiber; (E) PVDF(TBT)/PVP(TBT)- $\mathrm{H}_{2} \mathrm{O}$ nanofiber, and (F) PVDF(TBT)/PVP(TBT)-GQDs nanofiber.

Figure 4 shows the x-ray diffraction (XRD) pattern of the PVDF(TBT)/PVP(TBT)-GQDs photocatalyst. The XRD pattern shows that the peaks of the PVDF(TBT)/PVP(TBT)-GQDs photocatalyst we prepared are in agreement with the $\mathrm{TiO}_{2}$ standard cards (PDF\#21-1272 is a standard card of $\mathrm{TiO}_{2}$ [54]. The characteristic diffraction peaks at 25.198, 36.867, 37.756, 38.467, 48.057, 53.857, $55.047,62.448,62.626,68.782,70.314,74.815,75.061$, and 76.005 correspond to the (101), (103), (004), (112), (200), (105), (211), (213), (204), (116), (220), (107), (215), and (301) planes of $\mathrm{TiO}_{2}$, indicating the existence of anatase $\mathrm{TiO}_{2}$. Figure 4 shows that the $\mathrm{TiO}_{2}$ was successfully attached to the PVDF(TBT)/PVP(TBT)-GQDs photocatalysts, which can significantly improve the photocatalytic performance of the PVDF(TBT)/PVP(TBT)-GQDs photocatalyst. 


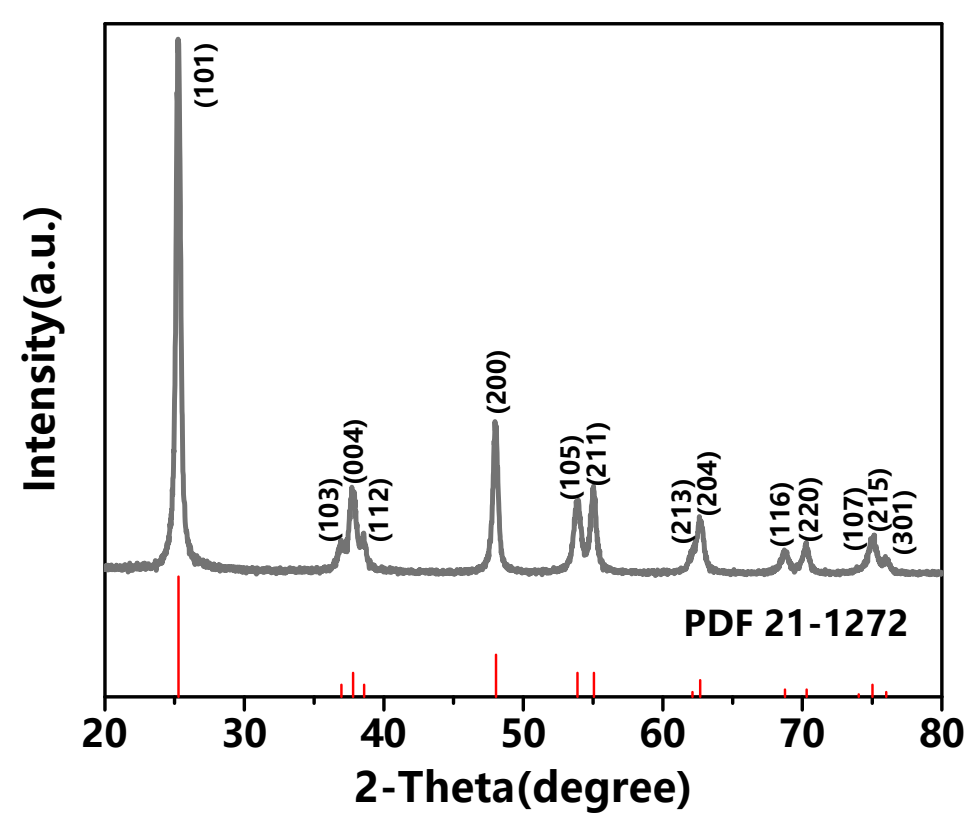

Figure 4. XRD pattern of PVDF(TBT)/PVP(TBT)-GQDs photocatalyst.

The photocatalyst was also examined with x-ray photoelectron spectroscopy (XPS). Among them, in the XPS measurement, we used C1s $(284.8 \mathrm{eV})$ for energy calibration. Figure 5A is a full-scan XPS spectrum of the PVDF(TBT)/PVP(TBT)-GQDs photocatalyst. As shown in Figure 5A, the peak at $284.7 \mathrm{eV}$ can be assigned to $\mathrm{C} 1 \mathrm{~s}$ while the peak at $530.7 \mathrm{eV}$ can be assigned to $\mathrm{O} 1 \mathrm{~s}$ [55]. In addition, there was a weak N1s peak at $397.7 \mathrm{eV}$ and a weak F1s peak at $689.7 \mathrm{eV}$. This indicates that the prepared GQDs contained not only $\mathrm{C}$ and $\mathrm{O}$ elements, but also a small amount of $\mathrm{N}$ elements, which is in agreement with Zhu et.al [56]. Figure 5B is a C1s high-resolution XPS spectrum of the PVDF(TBT)/PVP(TBT)-GQDs photocatalyst [53,57-60]. Multimodal fitting of the XPS spectrum can obtain three peaks, located at $284.7 \mathrm{eV}$ (red), $285.7 \mathrm{eV}$ (pink), and $288.1 \mathrm{eV}$ (blue), respectively. These three peak positions correspond to $\mathrm{C}=\mathrm{C}$ (red), $\mathrm{C}-\mathrm{C} / \mathrm{C}-\mathrm{H}$ (pink), and $\mathrm{C}-\mathrm{O}$ (blue). Among them, the ratio of the $\mathrm{C}=\mathrm{C}$ bond was the highest among all functional groups, indicating that the $\mathrm{C}=\mathrm{C}$ bond is the most important functional group among the resultant GQDs. The low $\mathrm{C}-\mathrm{O}$ content indicates that the prepared GQDs have a low oxygen content. 

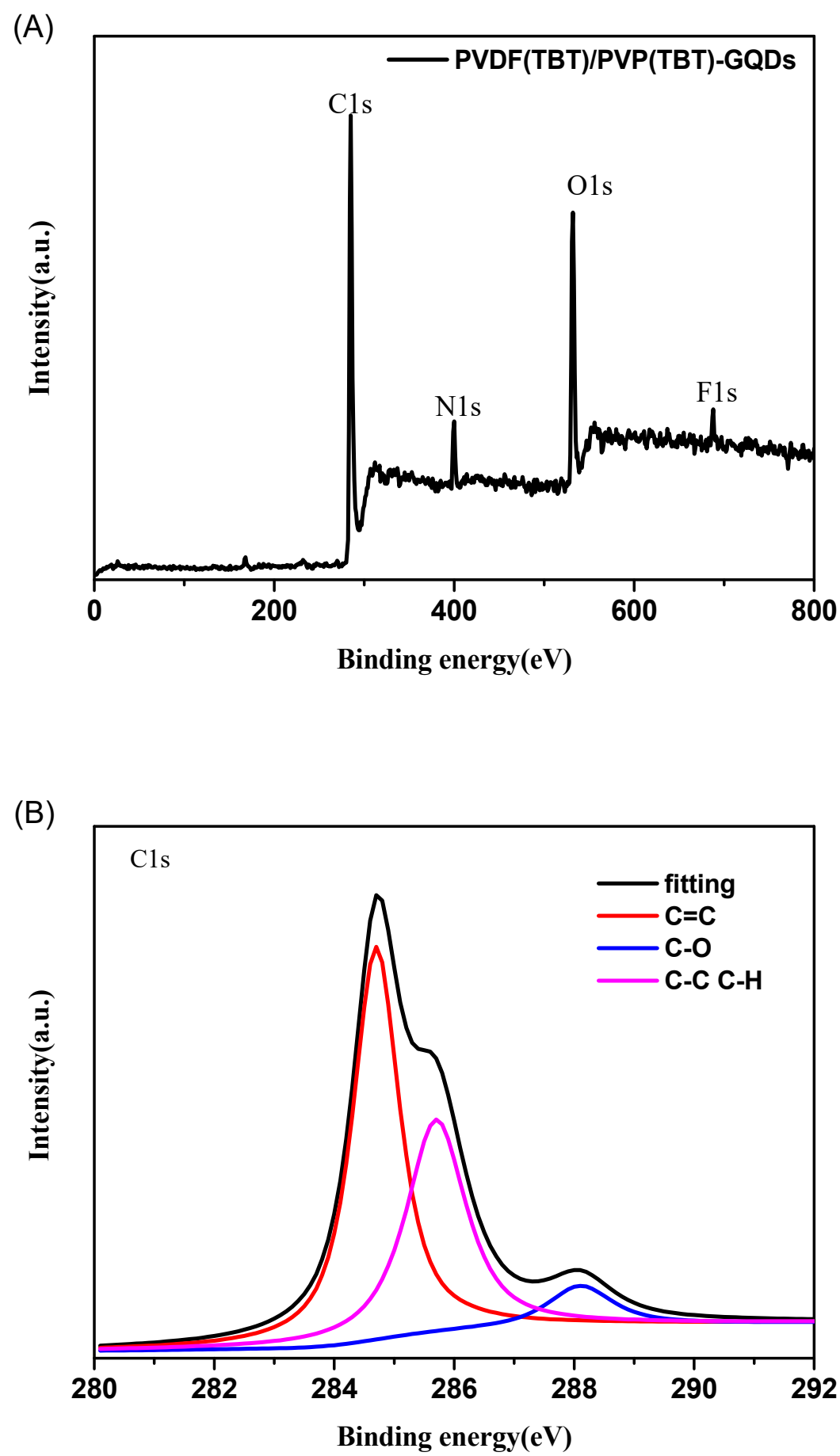

Figure 5. (A) The XPS full spectrum of PVDF(TBT)/PVP(TBT)-GQDs (B) The C1s XPS spectrum of PVDF(TBT)/PVP(TBT)-GQDs.

To further study the functional groups contained in the PVDF(TBT)/PVP(TBT)-GQDs photocatalysts, the infrared spectra of photocatalysts was also performed. Figure 6 shows the infrared spectrum of the PVDF(TBT)/PVP(TBT)-GQDs photocatalyst. As can be seen in Figure 6, the vibration peaks of $\mathrm{C}=\mathrm{C}, \mathrm{C}-\mathrm{H}, \mathrm{C}-\mathrm{C}$, and $\mathrm{C}-\mathrm{O}$ of the GQDs corresponded to $1617.41 \mathrm{~cm}^{-1}, 1401.09 \mathrm{~cm}^{-1}$, $1180.41 \mathrm{~cm}^{-1}$, and $1068.91 \mathrm{~cm}^{-1}$, respectively. As can be seen from Figures 5 and 6, the functional groups measured with the infrared spectrum matched well with the XPS spectra. 


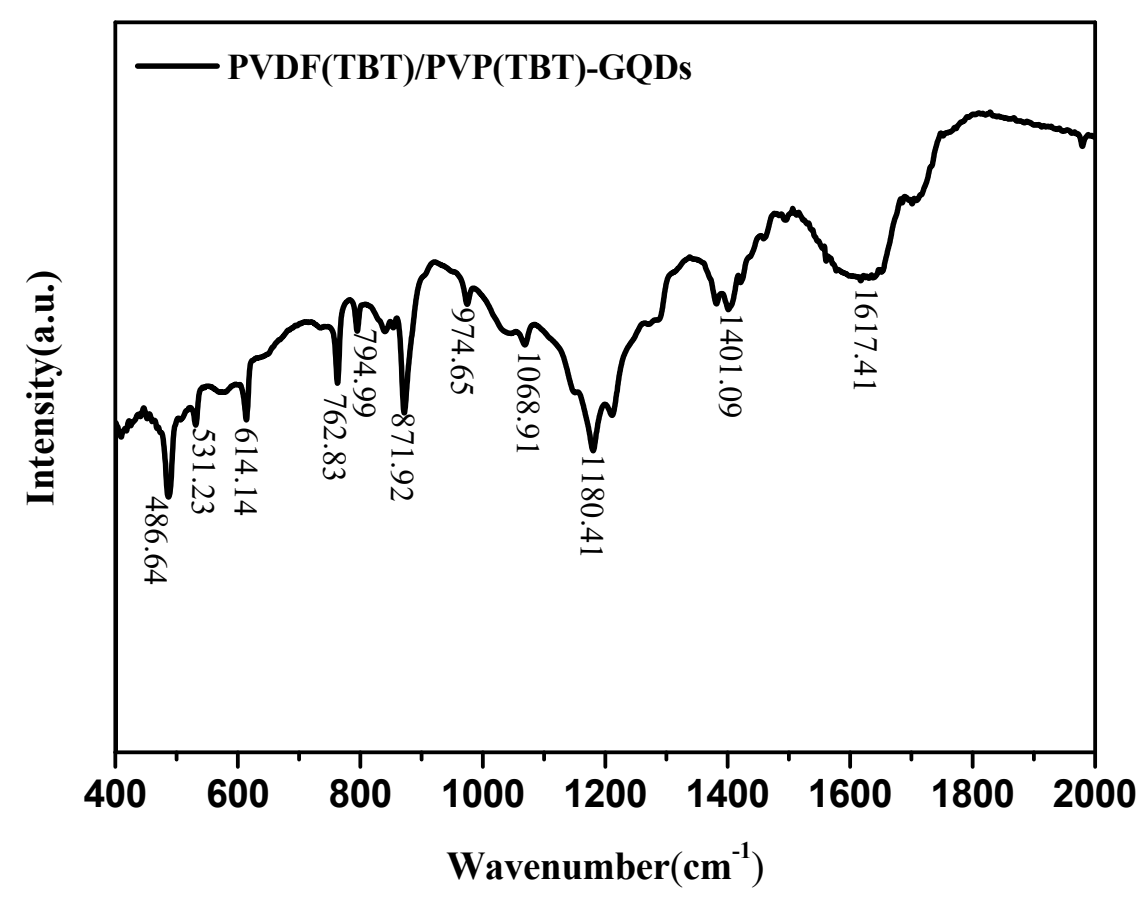

Figure 6. The infrared spectra of PVDF(TBT)/PVP(TBT)-GQDs.

\subsection{Photocatalytic Activity}

An $800 \mathrm{~W}$ xenon lamp was used to simulate the solar radiation source. The photocatalytic performance of the prepared photocatalyst was examined by decomposition of the RhB solution. In this study, PVDF(TBT)- $\mathrm{H}_{2} \mathrm{O}, \mathrm{PVDF}(\mathrm{TBT})-\mathrm{GQDs}$, PVDF(TBT)/PVP(TBT)- $\mathrm{H}_{2} \mathrm{O}$, and PVDF(TBT)/PVP(TBT)-GQDs films with a size of $2 \mathrm{~cm} \times 2 \mathrm{~cm}$ were placed in a quartz tube containing $50 \mathrm{~mL}$ of $\mathrm{RhB}$ solution. The initial concentration of RhB solution was $15 \mathrm{mg} / \mathrm{L}$. Meanwhile, a blank control group was also set. The results of the RhB degradation experiments showed that the degradation rates of the PVDF(TBT) $-\mathrm{H}_{2} \mathrm{O}, \mathrm{PVDF}(\mathrm{TBT}) / \mathrm{PVP}(\mathrm{TBT})-\mathrm{H}_{2} \mathrm{O}, \mathrm{PVDF}(\mathrm{TBT})-\mathrm{GQDs}$, and PVDF(TBT)/PVP(TBT)-GQDs photocatalysts were $9.66 \%, 12.08 \%, 47.71 \%$, and $97.16 \%$ after $210 \mathrm{~min}$. The reaction rate of the PVDF(TBT)- $\mathrm{H}_{2} \mathrm{O}, \mathrm{PVDF}(\mathrm{TBT}) / \mathrm{PVP}(\mathrm{TBT})-\mathrm{H}_{2} \mathrm{O}, \mathrm{PVDF}(\mathrm{TBT})-\mathrm{GQDs}$, and PVDF(TBT)/PVP(TBT)-GQDs photocatalysts to the RhB solution was $0.0069 \mathrm{mg} / \mathrm{L} \cdot \mathrm{min}, 0.0086 \mathrm{mg} / \mathrm{L} \cdot \mathrm{min}$, $0.0340 \mathrm{mg} / \mathrm{L} \cdot \mathrm{min}$ and $0.0649 \mathrm{mg} / \mathrm{L} \cdot \mathrm{min}$, respectively. Among them, PVDF(TBT)/PVP(TBT)-GQDs $(0.0649 \mathrm{mg} / \mathrm{L} \cdot \mathrm{min})$ and PVDF(TBT)-GQDs $(0.0340 \mathrm{mg} / \mathrm{L} \cdot \mathrm{min})$ showed an 8 and 3.9 times higher photocatalytic efficiency than the other photocatalysts (PVDF(TBT)- $\left.\mathrm{H}_{2} \mathrm{O}, \mathrm{PVDF}(\mathrm{TBT}) / \mathrm{PVP}(\mathrm{TBT})-\mathrm{H}_{2} \mathrm{O}\right)$, respectively. In particular, the PVDF(TBT)/PVP(TBT)-GQDs photocatalyst only took $210 \mathrm{~min}$ to degrade $97.16 \%$ of the RhB solution, as shown in Figure 7.

Figure 8 shows the UV-Visible absorption spectra of the photocatalysts $\mathrm{PVDF}(\mathrm{TBT})-\mathrm{H}_{2} \mathrm{O}$, PVDF(TBT)-GQDs, PVDF(TBT)/PVP(TBT)- $\mathrm{H}_{2} \mathrm{O}$, and PVDF(TBT)/PVP(TBT)-GQDs. The absorption edges of $\mathrm{PVDF}(\mathrm{TBT})-\mathrm{H}_{2} \mathrm{O}$ and $\mathrm{PVDF}(\mathrm{TBT}) / \mathrm{PVP}(\mathrm{TBT})-\mathrm{H}_{2} \mathrm{O}$ were around $\sim 370 \mathrm{~nm}$, which are the absorption of $\mathrm{TiO}_{2}$. After graphene doping, the absorption edges were extended to over $800 \mathrm{~nm}$, which fell into the near infrared range. The absorption results are in good agreement with the photocatalytic performance. Both the PVDF(TBT)-GQDs and PVDF(TBT)/PVP(TBT)-GQDs photocatalyst maintained a high light absorption efficiency underlying irradiation from $200 \mathrm{~nm}$ to $800 \mathrm{~nm}$. In particular, for PVDF(TBT)/PVP(TBT)-GQDs, the lowest absorption rate of the entire process reached $60 \%$. In contrast, the two photocatalysts, $\mathrm{PVDF}(\mathrm{TBT})-\mathrm{H}_{2} \mathrm{O}$ and $\mathrm{PVDF}(\mathrm{TBT}) / \mathrm{PVP}(\mathrm{TBT})-\mathrm{H}_{2} \mathrm{O}$, have specific light absorption in the $200-350 \mathrm{~nm}$ wavelength range, but the light absorption efficiency is negligible in the $350-800 \mathrm{~nm}$ wavelength range. Therefore, PVDF(TBT)-GQDs and PVDF(TBT)/PVP(TBT)-GQDs photocatalysts with attached GQDs can maintain high light absorption efficiency under sunlight. This is one of the 
reasons why the PVDF(TBT)-GQDs and PVDF(TBT)/PVP(TBT)-GQDs photocatalyst showed higher degradation rates.

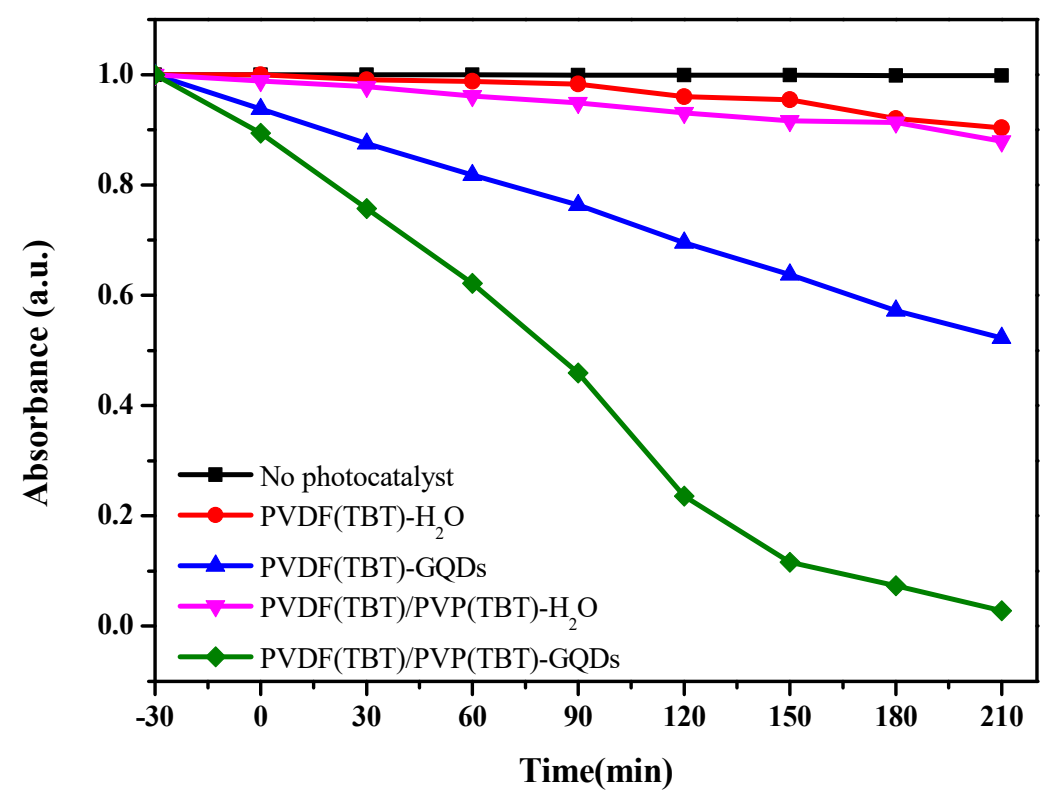

Figure 7. Degradation rate of $\mathrm{RhB}$ by the photocatalyst prepared without the photocatalyst, PVDF(TBT)- $\mathrm{H}_{2} \mathrm{O}$, PVDF(TBT)-GQDs, PVDF(TBT)/PVP(TBT)- $\mathrm{H}_{2} \mathrm{O}$, and PVDF(TBT)/PVP(TBT)-GQDs.

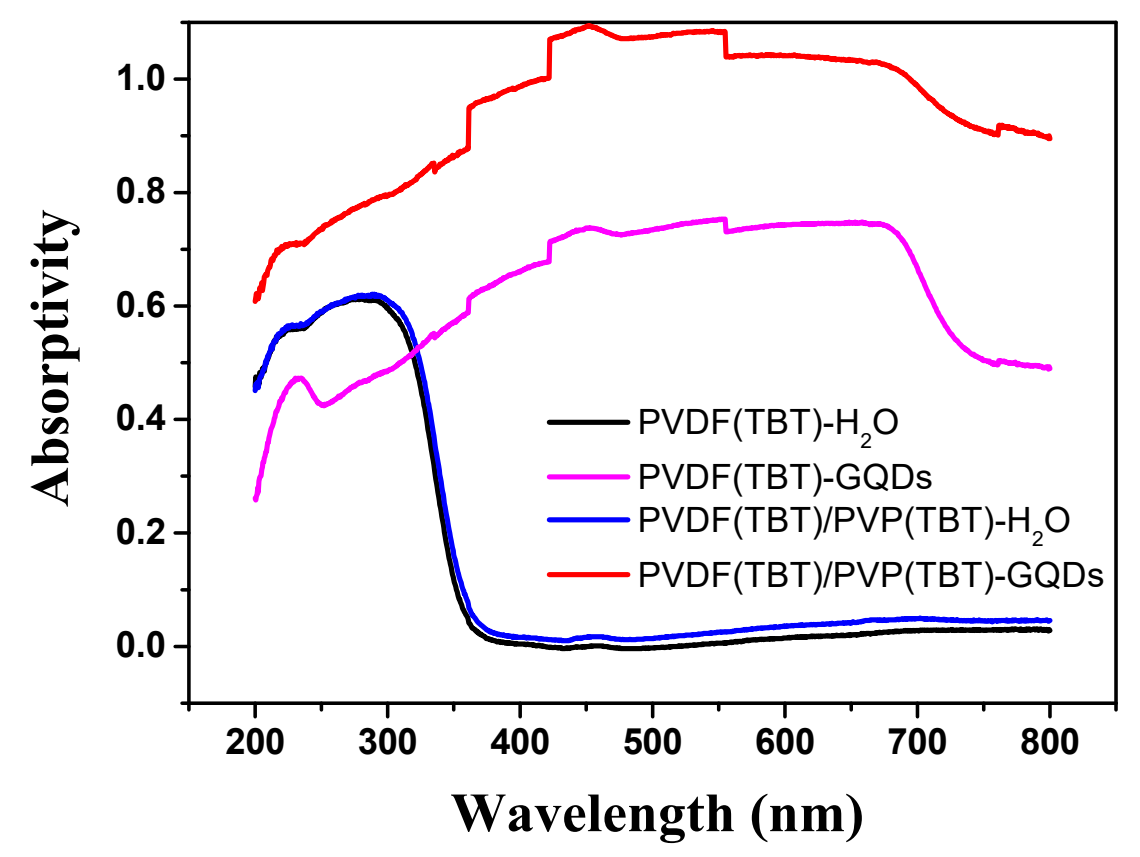

Figure 8. UV-Visible absorption spectra of the PVDF(TBT)- $\mathrm{H}_{2} \mathrm{O}$, PVDF(TBT)-GQDs, PVDF(TBT)/PVP(TBT)- $\mathrm{H}_{2} \mathrm{O}$, and PVDF(TBT)/PVP(TBT)-GQDs photocatalyst.

The Brunauer-Emmett-Teller (BET) measurement results showed that the specific surface areas of the PVDF(TBT)- $\mathrm{H}_{2} \mathrm{O}, \mathrm{PVDF}(\mathrm{TBT}) / \mathrm{PVP}(\mathrm{TBT})-\mathrm{H}_{2} \mathrm{O}, \mathrm{PVDF}(\mathrm{TBT})-\mathrm{GQDs}$, and PVDF(TBT)/PVP(TBT)-GQDs photocatalyst were $4.346 \mathrm{~m} / \mathrm{g}, 6.429 \mathrm{~m} / \mathrm{g}, 12.941 \mathrm{~m} / \mathrm{g}$, and $16.037 \mathrm{~m} / \mathrm{g}$, respectively. Obviously, the PVDF(TBT)/PVP(TBT) film showed a larger specific surface area than that of the PVDF(TBT) film. In addition, the adhesion of GQDs can effectively increase the specific surface area of the photocatalyst. Increasing the specific surface area increases the interaction 
between the photocatalyst and the RhB solution, improving the photocatalytic efficiency of the photocatalyst. Moreover, the introduction of GQDs can effectively extend the lifetime of photogenerated carriers, thus improving the photocatalytic efficiency of the photocatalyst [12]. On one hand, the dissolution of PVP during the hydrothermal reaction, leads to an increase in the specific surface area of the PVDF(TBT)/PVP(TBT)-GQDs photocatalyst. On the other hand, the hydrothermal method can effectively attach GQDs onto the PVDF(TBT)/PVP(TBT) film, which further improves the photocatalytic efficiency of PVDF(TBT)/PVP(TBT)-GQDs. Among other photocatalysts (PVDF(TBT)-GQDs, PVDF(TBT)/PVP(TBT)- $\mathrm{H}_{2} \mathrm{O}$, and PVDF(TBT)- $\mathrm{H}_{2} \mathrm{O}$ ), the PVDF(TBT)-GQDs photocatalysts with attached GQDs showed higher photocatalytic efficiency. For the PVDF(TBT)/PVP(TBT)- $\mathrm{H}_{2} \mathrm{O}$ and $\mathrm{PVDF}(\mathrm{TBT})-\mathrm{H}_{2} \mathrm{O}$ photocatalysts, their photocatalytic efficiency was lower under the xenon lamp. It should be noted that the PVDF(TBT)/PVP(TBT)-GQDs photocatalyst was broken to pieces after the photocatalytic experiment, which does not facilitate the recovery and reuse of the photocatalyst, although it shows good photocatalytic efficiency.

\section{Conclusions}

In summary, we successfully synthesized PVDF(TBT)/PVP(TBT)-GQDs, PVDF(TBT)/PVP(TBT)- $\mathrm{H}_{2} \mathrm{O}$, PVDF(TBT)-GQDs, and PVDF(TBT)- $\mathrm{H}_{2} \mathrm{O}$ photocatalysts by combining both electrospinning and hydrothermal methods. First, a PVDF(TBT)/PVP(TBT) film was prepared via electrospinning, and then PVP was dissolved to prepare a porous photocatalyst with a large specific surface area. Meanwhile, the GQDs were attached to the photocatalyst. The PVDF(TBT)/PVP(TBT)-GQDs photocatalyst showed the best photocatalytic efficiency. The PVDF(TBT)/PVP(TBT)-GQDs photocatalyst can degrade a $97.16 \%$ RhB solution within $210 \mathrm{~min}$, under $800 \mathrm{~W}$ xenon lamp irradiation. Our laboratory is currently conducting research to increase the strength of PVDF(TBT)/PVP(TBT)-GQDs photocatalysts in order to improve the recycling performance of the photocatalysts.

Author Contributions: Y.W., Y.-Z.L. and Z.C. conceived and designed the experiments; F.Z. performed the experiments; Z.C., F.Z., C.Y., X.-X.W., R.L., Z.W., and X.W. analyzed the data; Y.-L. and Y.W. supervised and contributed reagents and analysis tools; F.Z. wrote the manuscript; Z.C. supervised and revised the manuscript. All authors have read and agreed to the published version of the manuscript.

Funding: This research was funded by the National Natural Science Foundation of China (Grant Nos. 51673103,51703102 and 51973100), the National Natural Science Foundation of China $(51,703,102)$, the joint French-Singaporean MERLION program (Grant No. R279,000,334,133), and the Taishan Scholars Program of Shandong Province.

Conflicts of Interest: The authors declare no conflict of interest.

\section{References}

1. Fujishima, A.; Honda, K. Electrochemical photolysis of water at a semiconductor electrode. Nature 1972, 238, 37-38. [CrossRef] [PubMed]

2. Rao, K.V.S.; Rachel, A.; Subrahmanyam, M.; Boule, P. Immobilization of $\mathrm{TiO}_{2}$ on pumice stone for the photocatalytic degradation of dyes and dye industry pollutants. Appl. Catal. B Environ. 2003, 46, 77-85.

3. Hu, L.; Flanders, P.M.; Miller, P.L.; Strathmann, T.J. Oxidation of sulfamethoxazole and related antimicrobial agents by $\mathrm{TiO}_{2}$ photocatalysis. Water Res. 2007, 41, 2612-2626. [CrossRef] [PubMed]

4. Park, H.; Park, Y.; Kim, W.; Choi, W. Surface modification of $\mathrm{TiO}_{2}$ photocatalyst for environmental applications. J. Photochem. Photobiol. C 2013, 15, 1-20. [CrossRef]

5. Dong, H.; Zeng, G.; Tang, L.; Fan, C.; Zhang, C.; He, X.; He, Y. An overview on limitations of TiO $\mathrm{T}_{2}$-based particles for photocatalytic degradation of organic pollutants and the corresponding countermeasures. Water Res. 2015, 79, 128-146. [CrossRef] [PubMed]

6. Ni, M.; Leung, M.K.H.; Leung, D.Y.C.; Sumathy, K. A review and recent developments in photocatalytic water-splitting using for hydrogen production. Renew. Sustain. Energy Rev. 2007, 11, 401-425. [CrossRef]

7. Wu, T.; Liu, G.; Zhao, J. Photoassisted Degradation of Dye Polltants. V. Self-Photosensitized Oxidative Transformation of Rhodamine B Under Visible Light Irradiation in Aqueous $\mathrm{TiO}_{2}$ Dispersions. J. Phys. Chem. B 1998, 102, 5845-5851. [CrossRef] 
8. Arabatzis, I.M.; Stergiopoulos, T.; Bernard, M.C.; Labou, D.; Neophytides, S.G.; Falaras, P. Silver-modified titanium dioxide thin films for efficient photodegradation of methyl orange. Appl. Catal. B Environ. 2003, 42, 187-201. [CrossRef]

9. Zhang, X.; Jia, H.P.; Du, A.J.; Fu, W.; Sun, D.D.; Leckie, J.O. Combination of one-dimensional TiO $\mathrm{T}_{2}$ nanowire photocatalytic oxidation with microfiltration for water treatment. Water Res. 2009, 43, 1179-1186. [CrossRef]

10. Hur, J.S.; Koh, Y. Bactericidal activity and water purification of immobilized $\mathrm{TiO}_{2}$ photocatalyst in bean sprout cultivation. Biotechnol. Lett. 2002, 24, 23-25. [CrossRef]

11. Ao, C.H.; Lee, S.C. Indoor air purification by photocatalyst $\mathrm{TiO}_{2}$ immobilized on an activated carbon filter installed in an air cleaner. Chem. Eng. Sci. 2005, 60, 103-109. [CrossRef]

12. Zhang, F.; Wang, X.; Liu, H.; Liu, C.; Wan, Y.; Long, Y.; Cai, Z. Recent Advances and Applications of Semiconductor Photocatalytic Technology. Appl. Sci. 2019, 9, 2489. [CrossRef]

13. El-Bahy, Z.M.; Ismail, A.A.; Mohamed, R.M. Enhancement of titania by doping rare earth for photodegradation of organic dye (Direct Blue). J. Hazard. Mater. 2009, 166, 138-143. [CrossRef] [PubMed]

14. Viveroescoto, J.L.; Chiang, Y.D.; Wu, K.C.; Yamauchi, Y. Recent progress in mesoporous titania materials: Adjusting morphology for innovative applications. Sci. Technol. Adv. Mater. 2012, 13, 013003. [CrossRef]

15. Zhou, R.; Zhang, Q.; Uchaker, E.; Lan, J.; Yin, M.; Cao, G. Mesoporous $\mathrm{TiO}_{2}$ beads for high efficiency $\mathrm{CdS} / \mathrm{CdSe}$ quantum dot co-sensitized solar cells. J. Mater. Chem. A 2014, 2, 2517-2525. [CrossRef]

16. Zhang, Z.; Shao, C.; Zhang, L.; Li, X.; Liu, Y. Electrospun nanofibers of V-doped $\mathrm{TiO}_{2}$ with high photocatalytic activity. J. Colloid Interface Sci. 2010, 351, 57-62.

17. Cai, Z.; Teng, J.; Xiong, Z.; Li, Y.; Li, Q.; Lu, X.; Zhao, X.S. Fabrication of $\mathrm{TiO}_{2}$ Binary Inverse Opals without Overlayers via the Sandwich-Vacuum Infiltration of Precursor. Langmuir 2011, 27, 5157-5164. [CrossRef]

18. Cai, Z.; Xiong, Z.; Lu, X.; Teng, J. In situ gold-loaded titania photonic crystals with enhanced photocatalytic activity. J. Mater. Chem. A 2014, 2, 545-553. [CrossRef]

19. Bian, Z.; Tachikawa, T.; Zhang, P.; Fujitsuka, M.; Majima, T. Au/ $\mathrm{TiO}_{2}$ superstructure-based plasmonic photocatalysts exhibiting efficient charge separation and unprecedented activity. J. Am. Chem. Soc. 2014, 136, 458-465.

20. Zhang, H.; Quan, X.; Chen, S.; Zhao, H. Fabrication and characterization of silica/titania nanotubes composite membrane with photocatalytic capability. Environ. Sci. Technol. 2006, 40, 6104-6109.

21. Geng, W.; Da, C.; Hao, Z.; Zhang, J.Z.; Li, J. Tunable Photocurrent Spectrum in Well-Oriented Zinc Oxide Nanorod Arrays with Enhanced Photocatalytic Activity. J. Phys. Chem. C 2008, 112, 8850-8855.

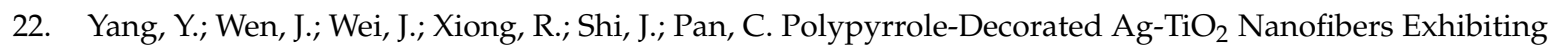
Enhanced Photocatalytic Activity under Visible-Light Illumination. ACS Appl. Mater. Interfaces 2013, 5, 6201-6207. [CrossRef] [PubMed]

23. Liu, R.; Huang, H.; Li, H. Metal Nanoparticle/Carbon Quantum Dot Composite as a Photocatalyst for High-Efficiency Cyclohexane Oxidation. ACS Catal. 2014, 4, 328-336. [CrossRef]

24. Guo, Y.; Yao, P.; Zhu, D. A novel method for the development of a carbon quantum dot/carbon nitride hybrid photocatalyst that responds to infrared light irradiation. J. Mater. Chem. A 2015, 3, 13189-13192. [CrossRef]

25. Miao, R.; Luo, Z.; Zhong, W. Mesoporous $\mathrm{TiO}_{2}$ modified with carbon quantum dots as a high-performance visible light photocatalyst. Appl. Catal. B Environ. 2016, 189, 26-38. [CrossRef]

26. Li, C.; Xin, W.; Meziani, M.J.; Fushen, L.; Haifang, W.; Luo, P.G.; Yi, L.; Harruff, B.A.; Monica, V.L.; Davoy, M. Carbon dots for multiphoton bioimaging. J. Am. Chem. Soc. 2007, 129, 11318-11319.

27. Zhao, Q.L.; Zhang, Z.L.; Huang, B.H.; Peng, J.; Zhang, M.; Pang, D.W. Facile preparation of low cytotoxicity fluorescent carbon nanocrystals by electrooxidation of graphite. Chem. Commun. 2008, 41, 5116-5118. [CrossRef]

28. Li, C.; Sushant, S.; Parambath, A.; Bunker, C.E.; Juan, X.; Fernando, K.A.S.; Ping, W.; Guliants, E.A.; Tackett, K.N.; Ya-Ping, S. Carbon nanoparticles as visible-light photocatalysts for efficient $\mathrm{CO}_{2}$ conversion and beyond. J. Am. Chem. Soc. 2011, 133, 4754-4757.

29. Yu, H.; Zhao, Y.; Zhou, C.; Shang, L.; Peng, Y.; Cao, Y.; Wu, L.Z.; Tung, C.H.; Zhang, T. Carbon quantum dots $/ \mathrm{TiO}_{2}$ composites for efficient photocatalytic hydrogen evolution. J. Mater. Chem. A 2014, 2, 3344-3351. [CrossRef]

30. Song, P.; Zhang, X.; Sun, M.; Cui, X.; Lin, Y. Graphene oxide modified $\mathrm{TiO}_{2}$ nanotube arrays: Enhanced visible light photoelectrochemical properties. Nanoscale 2012, 4, 1800-1804. [CrossRef] 
31. Zhu, S.; Zhang, J.; Liu, X.; Li, B.; Wang, X.; Tang, S.; Meng, Q.; Li, Y.; Shi, C.; Hu, R. Graphene Quantum Dots with Controllable Surface Oxidation, Tunable Fluorescence and up-Conversion Emission. RSC Adv. 2012, 2, 2717-2720. [CrossRef]

32. Li, M.; Ni, W.; Kan, B.; Wan, X.; Zhang, L.; Zhang, Q.; Chen, Y.Z. Graphene quantum dots as the hole transport layer material for high-performance organic solar cells. Phys. Chem. Chem. Phys. 2013, 15, 18973-18978.

33. Jin, S.H.; Kim, D.H.; Jun, G.H.; Hong, S.H.; Jeon, S. Tuning the photoluminescence of graphene quantum dots through the charge transfer effect of functional groups. ACS Nano 2013, 7, 1239-1245.

34. Zhang, Z.; Jing, Z.; Nan, C.; Qu, L. Graphene Quantum Dots: An Emerging Material for Energy-Related Applications and beyond. Energy Environ. Sci. 2012, 5, 8869-8890. [CrossRef]

35. Yang, H.B.; Dong, Y.Q.; Wang, X.; Khoo, S.Y.; Liu, B. Cesium carbonate functionalized graphene quantum dots as stable electron-selective layer for improvement of inverted polymer solar cells. ACS Appl. Mater. Interfaces 2014, 6, 1092-1099. [CrossRef]

36. Wang, Z.; Zeng, H.; Sun, L. Graphene quantum dots: Versatile photoluminescence for energy, biomedical, and environmental applications. J. Mater. Chem. C 2015, 3, 1157-1165. [CrossRef]

37. Israa, A.O.; Honglei, G.; Aguilar, Z.P.; Shouwu, G.; Melconian, A.K.; Al-Kazaz, A.K.A.; Fanke, M.; Nianqiang, W. Detection of the ovarian cancer biomarker CA-125 using chemiluminescence resonance energy transfer to graphene quantum dots. Chem. Commun. 2014, 50, 1344-1346.

38. Zhou, Y.; Qu, Z.B.; Zeng, Y.; Zhou, T.; Shi, G. A novel composite of graphene quantum dots and molecularly imprinted polymer for fluorescent detection of paranitrophenol. Biosens. Bioelectron. 2014, 52, 317-323. [CrossRef]

39. Mo, Z.; Bai, L.; Shang, W.; Xie, W.; Hong, M.; Fu, Y.; Fang, D.; Hui, S.; Fan, L.; Mei, H. Facile Synthesis of Water-Soluble, Highly Fluorescent Graphene Quantum Dots as a Robust Biological Label for Stem Cells. J. Mater. Chem. 2012, 22, 7461-7467.

40. Sun, H.; Wu, L.; Gao, N.; Ren, J.; Qu, X. Improvement of photoluminescence of graphene quantum dots with a biocompatible photochemical reduction pathway and its bioimaging application. ACS Appl. Mater. Interfaces 2013, 5, 1174-1179. [CrossRef]

41. Qu, D.; Sun, Z.; Zheng, M.; Li, J.; Zheng, Y.; Zheng, G.; Xie, Z. Three Colors Emission from S,N Co-doped Graphene Quantum Dots for Visible Light $\mathrm{H}_{2}$ Production and Bioimaging. Adv. Opt. Mater. 2015, 3, 360-367.

42. Reitzenstein, N.H.V.; Bi, X.; Yu, Y.; Hristovski, K.; Westerhoff, P. Morphology, structure, and properties of metal oxide/polymer nanocomposite electrospun mats. J. Appl. Polym. Sci. 2016, 133, 43811-43819.

43. Choi, S.S.; Lee, Y.S.; Joo, C.W. Electrospun PVDF nanofiber web as polymer electrolyte or separator. Electrochim. Acta 2004, 50, 339-343. [CrossRef]

44. Liao, Y.; Wang, R.; Tian, M. Fabrication of polyvinylidene fluoride (PVDF) nanofiber membranes by electro-spinning for direct contact membrane distillation. J. Membr. Sci. 2013, 425, 30-39. [CrossRef]

45. He, T.; Zhou, Z.; Xu, W. Preparation and photocatalysis of $\mathrm{TiO}_{2}$-fluoropolymer electrospun fiber nanocomposites. Polymer 2009, 50, 3031-3036. [CrossRef]

46. Lemal, D.M. Perspective on fluorocarbon chemistry. J. Org. Chem. 2004, 35, 1-11. [CrossRef]

47. Lee, A.; Elam, J.W.; Darling, S.B. Membrane materials for water purification: Design, development, and application. Environ. Sci. Water Res. Technol. 2016, 2, 17-42. [CrossRef]

48. Singh, S.; Mahalingam, H.; Singh, P.K. Polymer-supported titanium dioxide photocatalysts for environmental remediation: A review. Appl. Catal. A Gen. 2013, 462, 178-195. [CrossRef]

49. Lu, X.; Zhao, Y.; Wang, C. Fabrication of CdS nanorods in PVP fiber matrices by electrospinning. Macromol. Rapid Commun. 2005, 26, 1325-1329. [CrossRef]

50. Bai, J.; Li, Y.; Li, M. Electrospinning method for the preparation of silver chloride nanoparticles in PVP nanofiber. Appl. Surf. Sci. 2008, 254, 4520-4523. [CrossRef]

51. Nasir, M.; Matsumoto, H.; Minagawa, M.; Tanioka, A.; Danno, T.; Horibe, H. Preparation of Porous PVDF Nanofiber from PVDF/PVP Blend by Electrospray Deposition. Polym. J. 2007, 39, 1060-1064. [CrossRef]

52. Jing, N.; Miao, Y.; Hu, Y.; Xu, Z. Tailoring the morphologies of PVDF nanofibers by interfacial diffusion during coaxial electrospinning. Mater. Des. 2016, 109, 264-269.

53. Yang, P.; Zhou, L.; Zhang, S. Facile synthesis and photoluminescence mechanism of graphene quantum dots. J. Appl. Phys. 2014, 116, 244306. [CrossRef]

54. Wilson, G.J.; Will, G.D.; Frost, R.L. Efficient microwave hydrothermal preparation of nanocrystalline anatase $\mathrm{TiO}_{2}$ colloids. J. Mater. Chem. 2002, 12, 1787-1791. [CrossRef] 
55. Zhang, S.; Holmes, T.; Lockshin, C. Spontaneous assembly of a self-complementary oligopeptide to form a stable macroscopic membrane. Proc. Natl. Acad. Sci. USA 1993, 90, 3334-3338. [CrossRef] [PubMed]

56. Zhu, S.; Zhang, J.; Tang, S. Surface chemistry routes to modulate the photoluminescence of graphene quanttma dots: From fluorescence mechanism to up-conversion bioimaging applications. Adv. Funct. Mater. 2012, 22, 4732-4740. [CrossRef]

57. Barone, V.; Hod, O.; Scuseria, G.E. Electronic structure and stability of semiconducting graphene nanoribbons. Nano Lett. 2006, 6, 2748-2754. [CrossRef]

58. Gu, W.; Zhang, W.; Li, X. Graphene sheets from worm-like exfoliated graphite. J. Mater. Chem. 2009, 19, 3367-3369. [CrossRef]

59. Seyed-Talebi, S.M.; Beheshtian, J.; Neek-Amal, M. Doping effect on the adsorption of $\mathrm{NH}_{3}$ molecule onto graphene quantum dot: From the physisorption to the chemisorption. J. Appl. Phys. 2013, 114, 124307-124313. [CrossRef]

60. Kim, S.; Hwang, S.W.; Kim, M.K. Anomalous behaviors of visible luminescence from graphene quantum dots: Interplay between size and shape. ACS Nano 2012, 6, 8203-8208. [CrossRef]

(C) 2020 by the authors. Licensee MDPI, Basel, Switzerland. This article is an open access article distributed under the terms and conditions of the Creative Commons Attribution (CC BY) license (http://creativecommons.org/licenses/by/4.0/). 